DESIGNING ENVIRONMENTS FOR COLLABORATIVE E-LEARNING

This is a post-print of an article submitted for consideration in the Educational Technology Research and Development (C) 2004 Springer Verlag.

Personal use of this manuscript is permitted. Permission from Springer Verlag must be obtained for any other commercial purpose.

This article may not exactly replicate the published version, due to editorial changes and/or formatting and corrections during the final stage of publication. Interested readers are advised to consult the published version which can be found at:

http://www.springerlink.com/content/w204530g786m0m83/

doi: $\{10.1007 / \mathrm{BF} 02504675\}$

Please refer this manuscript as:

Kirschner, P. A., Strijbos, J. W., Kreijns, K., \& Beers, P. (2004). Designing electronic collaborative learning environments. Educational Technology Research and Development, $52(3), 47-66$. 
Running head: DESIGNING ENVIRONMENTS FOR COLLABORATIVE E-LEARNING

Designing Electronic Collaborative Learning Environments

Paul Kirschner, Jan-Willem Strijbos, Karel Kreijns, Pieter Jelle Beers

Open University of the Netherlands 
Designing Electronic Collaborative Learning Environments

Current research on and design of collaborative learning environments - often referred to as Computer Supported Collaborative Learning (CSCL) Environments - tends to focus on surface level characteristics. Educational researchers and designers are busy, for example, determining optimal group size for problem-based education as opposed to project-centered learning. To determine optimal group size, students' collaborative efforts and the results of these efforts are compared for groups of varying size in different educational settings. This approach resembles comparative research on the use of different media in education that was strongly - and we had hoped definitively - criticized by both Clark (1983) and Reeves (1993). Such research focuses on the media used and surface characteristics of the education provided. This surface level approach disavows the fundamental differences between the real determinants of learning and behavior in education and results in learning materials that are unreliable or even mathemathantic.

A second problem is that educational institutions tend to apply traditional classroom ideas and pedagogy in non-contiguous collaborative learning environments, assuming that since these environments allow the interaction that we see in the classroom (e.g., chat, realtime meetings, and shared applications) traditional pedagogy can be used. Unfortunately these environments do not support such interactions in the same way that it occurs in face-to-face (i.e., time delay, lack of complete sensory contact, non-availability of off task activities, et cetera). The proximate result is often disgruntled or disappointed students and instructors, motivation that is quickly extinguished, poorly used environments, wasted time and money, and showcase environments that are often not much more than computer assisted page turning. The ultimate result is very similar to the first problem, no learning since the students tend to give up. 
The solution is as simple as it is elegant, namely attending not only to the technological prerequisites for collaboration (i.e., the technological environment), but also to the educational and social prerequisites for allowing collaboration to occur (i.e., the pedagogy and the social dynamics respectively). The educational part would take care of the first problem, namely choosing the right pedagogy to achieve one's aims and that take the characteristics of the media into account. The social part would enrich the chosen pedagogy by adding that element usually, almost automatically existent in contiguous learning, namely group formation and social dynamics within the group. This article provides a framework for designing such collaborative environments based upon the three prerequisites. It then goes into somewhat greater depth with respect to three non-surface level educational factors central to collaboration, namely task ownership, task character and task control. Finally conclusions are presented.

What follows is a discussion of three major issues of this article, namely (1) the role of three different types of affordances in stimulating and maintaining collaboration in primarily asynchronous distributed group learning (with emphasis on social affordances for group awareness), (2) interaction design and its use / power designing and developing technologically well-afforded electronic learning environments for collaborative learning, and (3) the role of tasks in educationally affording collaboration in asynchronous distributed groups. The article concludes with a description and the results of three projects dedicated to studying these three issues.

\section{Affording Collaboration}

Traditional instructional design is based upon insights from cognitive psychology (Kirschner, Van Merrienboer, Carr, \& Sloep, 2002) and as such is fairly deterministic or causal in that it tends to focus on individual learning outcomes by influencing or controlling instructional variables to create a learning environment that supports the acquisition of a 
specific skill (a certain person will acquire a specific skill through the implementation of a chosen learning method). Collaboration complicates using this approach. Here, individual and group level variables mediate the learning process such that it is nearly impossible to predefine conditions of learning or instruction such that interaction and skill acquisition are controlled.

Instead of a classic causal view, design of collaborative settings, due to the possible unforeseen interactions between group members, requires a more probabilistic or systemic view on design. This distinction is to a large extent similar to Van Merriënboer and Kirschner (2001) who distinguish between the World of Knowledge (outcome) and the World of Learning (process). In the world of knowledge, designers construct methods by which given learning goals in a specific subject matter domain can be attained by the learner. In the world of learning, designers focus on methods supporting learning processes, and not attainment of pre-defined goals (see Figure 1 from Strijbos, Martens \& Jochems, in press).

\section{****INSERT FIGURE 1 ABOUT HERE****}

This probabilistic view is similar to the systemic view (Merrill, 2002; Reigeluth, 1999; Van Merriënboer, 1997), except in the way that they handle complex interdependencies. In the systemic view complex interdependencies are specified in advance, whereas in the probabilistic view they are treated as unknowns and are not specified. A probabilistic design view - as opposed to a systemic design view - is more suited to collaborative environments because of the large number of individual group members' characteristics that may emerge (emergent properties) and affect interaction. These characteristics are difficult to specify making it almost impossible to specify their interdependencies.

This probabilistic view implies that more attention be paid to learning and interaction processes. Due to the interactions between learners, each person in a group may acquire a given skill through the chosen method, but may equally likely acquire only a part of the skill 
or the skill and something unforeseen. It might even be the case that the chosen method is abandoned by the group and replaced by another, more idiosyncratic method for that group. The question is not what outcomes specific educational techniques and collaborative work forms cause, but rather what activities they actually afford, also often referred to as the affordances of a learning environment. Specific types of learning need to be afforded in different ways (i.e., provide different opportunities for learning) because the learners perceive and interact with each other and with the environment differently.

What now are affordances? Roughly stated, they are opportunities for action; the perceived and actual fundamental properties of a thing that determine how the thing could possibly be used (Norman, 1988, p. 9). Affordances are most visible in real life. Some door handles, for example, look like they should be pulled. Their shape leads us to believe that this is the best way to use them. Other handles look like they should be pushed, a feature often indicated by a bar spanning the width of the door or even a flat plate on the side. Gibson (1977) originally proposed the concept of affordances to refer to the relationship between an object's physical properties and the characteristics of an actor (user) that enables particular interactions between actor and object. "The affordance of anything is a specific combination of the properties of its substance and its surfaces with reference to an animal" (Gibson, 1977, p. 67). These properties/surfaces interact with potential users and provide strong clues as to their operation.

An affordance is, by definition, characterized by two relationships. First, there must be a reciprocal relationship between the organism and the environment. For example, a fallen tree must have a certain size (i.e., it cannot be as large as a sequoia) and a person must have flexible knee and hip joints (unlike those of a giraffe that fold in the opposite direction) for the person to be able to sit on a log. The affordances must be perceivable and meaningful in that they can be used and must support or anticipate an action. Second, there must be a perception- 
action coupling. Once the need to do something (i.e., we get tired while walking in a forest) becomes salient (i.e., we perceive the fallen tree as a place where we can sit), the sitaffordance will not only invite but will also guide us to make use of the tree trunk to satisfy that need (action). The salience of the intervention may depend upon factors such as expectations, prior experiences, and/or focus of attention. In Gibson's view, natural selection has tuned a species' effectivities to the affordances associated with its niche or occupation (Allen \& Otto, 1996). In Gibson's (1977) terms, effectivities (i.e., one's capabilities for action) allow humans to exploit their world just as wings are the effectivities that allow birds to exploit the air for travel and the branches of trees to nest. In our view, the concept of affordances offers an alternative framework for designing and evaluating collaborative learning environments if appropriated to the educational context.

Education is always a unique combination of technological, social, and educational contexts and affordances. Classical educational contexts, for example, are often competitive (educational) and individual (social) with students working at their own place on their own (physical/technical). Group learning, on the other hand, makes use of collaborative or cooperative pedagogies (educational), in groups (social) and provides a group workspace with the necessary assortment of materials (physical/technical). CSCL represents yet another learning situation. The educational context is collaborative, the social context is the group, and the technological context is a computer-mediated one. The Open University of the Netherlands, for example, uses a computer-mediated communication environment (technological) for competency-based learning grounded in social constructivism (educational) with minimal direct contact, maximal guided individual study, and primarily asynchronous, text-based contact between students (social). 
When technology mediates the social and educational contexts such that their properties induce and invite specific learning behaviors, we speak of technology affording learning and education.

\section{Technological Affordances}

Norman (1988) links affordances to an object's usability, and thus these affordances are designated technological or technology affordances (Gaver, 1991). Usability is a wellknown objective of industrial or product design dealing with physical objects ranging from video-recorders to teapots, and human-computer interaction ( $\mathrm{HCI}$ ) dealing predominantly with graphical user interfaces composed of interface objects such as buttons and scrollbars. It is concerned with whether a system allows for the accomplishment of a set of tasks in an efficient and effective way that satisfies the user (e.g., Preece, Rogers, Sharp, Benyon, Holland, \& Carey, 1994). Neglecting usability criteria risks creating CSCL-environments that contain all the needed educational and social functionalities (in Nielsen's (1994) terms utility), but that cannot be handled by their users (i.e., the learners) because they are difficult to learn, access, and/or control. This is exemplified by Norman (1992) who maintains that the major problem with most new technological devices and programs - and in our opinion also in their use in education - "is that they are badly conceived, developed solely with the goal of using technology. They ignore completely the human side, the needs and the abilities of people who will presumably use the devices" (p. 65). An example of this is the escalator, a moving stairway that was designed to speed human traffic in a stairway by increasing a person's stair climbing speed with the speed of the moving stairs. As we all have probably experienced with the exception of the English - it has actually achieved the opposite! Large crowds tend to gather and cue at the top or bottom of the escalator because we tend to stand still on the escalator itself. This could be the result of human nature that was not entered into the design equation (i.e., inherent laziness), the non-ergonomic step-size that we encounter on almost all 
escalators (as we all have noticed when we have had to climb or descend an escalator that was out of order) or a combination of the two. Good design means taking the usability aspect into account, and thus requires a design process grounded in user-centered design research.

Later in this article we will discuss the fact that usability is a necessary although not sufficient factor when designing, developing and researching CSCL-environments. What is also needed is a particular design approach, namely that of interaction design.

\section{Social Affordances}

Kreijns, Kirschner, and Jochems (2002) define social affordances - analogous to technological affordances - as the "properties of a CSCL environment that act as socialcontextual facilitators relevant for the learner's social interaction" (p. 13). Objects that are part of the environment can realize these properties; hence they are designated social affordances devices. When social affordances are perceived, they invite learners to engage in activities that are in accordance with these affordances, that is, there can be social interaction.

In the physical world, affordances abound for casual and inadvertent interactions. In the virtual world, social affordances must be designed and must encompass two relationships. First, there must be a reciprocal relationship between group members and (different aspects of or devices in) the environment. The environment must fulfill the social intentions of members as soon as these intentions crop up while the social affordance devices must be meaningful and support or anticipate those social intentions. Second, there must be a perception-action coupling. Once a group-member steps onto the social stage and becomes salient (perception), the social affordance devices will not only invite, but will also allow, encourage or even guide another member to initiate a communication episode (action) with the salient member. Salience depends upon factors such as expectations, focus of attention, and/or current context of the fellow member. A CSCL environment bereft of social affordances is one that is likely one that isolates learners from their peers. 


\section{Educational Affordances}

Kirschner (2002) defines educational affordances as those characteristics of an artifact that determine if and how a particular learning behavior could possibly be enacted within a given context. In other words, the chosen educational artifact is instrumental in determining if and how individual and team learning (e.g., collaborative learning) can take place.

Educational affordances can be defined - analogous to social affordances - as the relationships between the properties of an educational intervention and the characteristics of the learners (for CSCL: learner and learning group) that enable particular kinds of learning by him/her (for CSCL: members of the group too).

Educational affordances in distributed learning groups encompass the same two relationships as all other affordances. The environment must fulfill the learning intentions of the member as soon as these intentions crop up while the affordances must be meaningful and must support or anticipate the learning intentions of the group-member. Further, once a learning need becomes salient (perception), the educational affordances of a device/ of a learning environment will not only invite but will also guide her/him to make use of a learning intervention to satisfy that need (action). The salience of the learning intervention and hence the degree of affordance of that intervention may depend upon factors such as expectations, prior experiences, and/or focus of attention.

\section{Design Guidelines}

At this point, it is clear what has to be designed, namely technical, educational and sociable CSCL environments. A next step is how such CSCL environments should be designed and implemented. Since affordances, as should be clear now, are not simply designable and developable features of a system - artifacts - but rather are dependent upon the relationship between the artifact and the organism - the user - the answer to that question is not simply one of interface design, but rather one of interaction design. Interaction design is 
closely linked, but different from human-computer interaction (HCI). As a relatively new field, there is yet no commonly agreed upon definition of interaction design and what the exact scope of this field is. In addition, it lacks a thorough theoretical framework although researchers are trying to propose one (e.g., Forlizzi \& Ford, 2000). However, it is clear that interaction design is concerned with aesthetics (or attractiveness) and emotion, and with the usability of user interfaces (Alben, 1997; Löwgren, 2002; Norman, 2002).

\section{Interaction Design and the User Experience}

In an attempt to define interaction design more precisely it is necessary to separate the two terms interaction and design, and look what definition or description applies to these. Shedroff (2001) sees interaction as a continuous process of action and reaction between two parties whether living or machines. Krippendorff (1989) elicits an etymology of design that goes back to the Latin root signare which means making something, distinguishing it by a sign, giving it significance, designating its relationship to other things, owners, users, or goods. Based on this original meaning Krippendorff states that design is making sense (of things). The two insights can be combined to construct a definition. Reimann (2001) defines interaction design as "a discipline dedicated to define the behavior of artifacts, environments, and systems (i.e., products)" ( $\mid$ How is interaction design different?). According to Thackara (2001) interaction design determines "the value of a communication service to its users, and the quality of experience they have when using it" ( $₫$ Why is interaction design important?).

As such, interaction design does not only concern itself with the usability, but also with the utility of the system - the set of functionalities a system incorporates. Together these form the usefulness of a system and are the goals of interaction design. A system that is usable but does not have the functionalities to support the user in what (s)he wants to accomplish is, de facto, worthless. In CSCL environments the utility is determined by both its educational and social functionality (see Figure 2). 


\section{****INSERT FIGURE 2 ABOUT HERE****}

Interaction design is also concerned with aesthetics and emotion, and how the interaction may appeal to and is benefiting to the users in a way that it absorbs the user within the interaction itself. Norman (2002) suggests that aesthetics and usability are as connected as affect and cognition. He claims to have evidence that pleasant things work better and are easier to learn, and that attractive things work better. In terms of social affordances, this means that designers should make the social affordance devices not only usable, but also attractive. A real-life example of such a social affordance device (at least for the youth) is the mobile phone. Although most mobile phones have similar functionalities and have comparable usability, some phones can be personalized by choosing a different front making the more attractive for their users. Even when another phone is easier to use, people still tend to prefer the more attractive phone. Likewise, this should be accomplished by social affordances devices in software.

The ultimate goal of interaction design can be summarized as the user experience. Preece, Rogers, and Sharp (2002) explain that interaction design is "about creating user experiences that enhance and extend the way people work, communicate and interact” (p. 6). If the user experience is the ultimate goal of interaction design, then it is important to define what user experience is and to determine whether or not it is one-dimensional. Kirschner (2002; Kirschner, Martens, \& Strijbos, 2004) presents a 6-stage model for interaction design of environments (see Figure 2). This model - as can be seen in the separate steps that it entails - is directed at determining the perceptibility, the usability and utility (i.e., the usefulness) of the reciprocal relationships, and the presence or absence of the required perception-action coupling of the affordances that the designer will or has implemented in her/his design. In this model, the designer must: 
1. Determine what learners actually do. Watch students interact, observe collaborating groups interacting to solve problems, observe users interacting with software, et cetera, and do this before designing and developing.

2. Determine what can be done to support those learners. Determine, based on stage 1, what actually needs to be supported/afforded and then proceed.

3. Determine the constraints of the learner, learning situation and learning environment and the conventions that already exist. Look further than the technological constraints and conventions and take into account the educational and social constraints and conventions that play a role in collaborative environments.

4. Determine how learners perceive and experience the support provided. There is a world of difference between (good) intentions and user perceptions thereof. Research and design must be carried out as iterative, interacting processes. New products must be tried out with intended users at stages in their development where physical and conceptual changes can still be made.

5. Determine how the learner actually uses the support provided. Analogous to stage 1, and following up the more formative evaluations carried out in stage 4 determine if the learner actually does what is hoped or expected.

6. Determine what has been learnt. The goal of education is learning and there are three standards to determine the success of any interaction design, namely its effectiveness, its efficiency and the satisfaction of those using it, in the case of CSCL-environments those learning and/or teaching. An increase in one or more of the standards without a concomitant decrease in any of the others means success. This is the proof of the pudding. 
These six stages provide a general approach to interaction design of instructional CSCL-environments. But, this design also needs to assure that the type of social interaction regarded to be supportive for competency development actually occurs. Thus, complementary to the 6-Stage Model, a more specific, process-oriented design methodology is needed which supplies the designer with those questions which must be answered in Stage 3 of the general design level (i.e., to determine the constraints of the learner, learning situation and learning environment). Process-oriented instructional methods may stimulate designers to adopt a probabilistic approach to CSCL design according to the expected interaction, paying attention to critical elements (constraints) affecting the interaction (see for example Strijbos, Martens, \& Jochems, in press).

Since most educational design for skills or competence-based education (e.g., problem-based, project-centered, case-based, et cetera) tends to focus on the task, we will focus more specifically on operationalizing educational affordances through a critical element that affords the interaction between students: the task. We regard task ownership, task character, and task control as defining factors in the educational affording of environments (see Figure 4).

\section{****INSERT FIGURE 4 ABOUT HERE****}

\section{Task Ownership}

Task ownership in a group is influenced by two pedagogical principles, namely individual accountability and positive interdependence. Individual accountability (Slavin, 1980) was introduced to counter the free rider or hitchhiking effect: some students would not invest any (or only a minimum of) effort into group performance. By stressing individual accountability, what the group does as a whole becomes less important. It is perfectly valid that in a group environment, each group member is individually accountable for his or her own work. For example, in many problem-based learning environments students' sense of 
individual ownership is increased through grading them for their individual effort, irrespective of the group's performance. Positive interdependence (Johnson, 1981) reflects the level to which group members are dependent upon each other for effective group performance (enhanced intra-group interaction). Positive interdependence holds that each individual can be held individually accountable for the work of the group and the group as a whole is responsible for the learning of each of the individual group members. Essential here is social cohesion and a heightened sense of belonging to a group. Positive interdependence is evident when group members in a project-centered learning environment carry out different tasks within a group project, all of which are needed in the final product. Interdependence can be stimulated through the tasks, resources, goals, rewards, roles or the environment itself (Brush, 1998).

Positive interdependence, in turn, provides the context within which promotive interaction takes place. According to Johnson and Johnson (1996), promotive interaction “exists when individuals encourage and facilitate each other's efforts to complete tasks in order to reach the group's goals." (p. 1028). In other words, individual accountability, positive interdependence, and promotive interaction counter the tendency towards hiding and anonymity.

\section{Task Character}

Traditional school tasks are artificial in that they are usually very well-structured, short in length, well-defined, oriented towards the individual, and designed to best fit the content and not reality, in other words these are designed to fit well into the World of Knowledge. An archetypical problem is: "Two trains traveling in opposite directions ..." At the other end of the continuum are real life (authentic) problems that are almost always illstructured (Mitroff, Mason, \& Bonoma, 1976) and/or wicked (introduced by Rittel \& Webber, 1973/1984; see also Conklin \& Weil, 1997). They are often so complex and multifaceted that 
they can only be solved by multidisciplinary groups working together, where the group members assuage cognitive conflict, elaborate on each other's contributions and co-construct shared representations and meaning. Examples of wicked problems are building a new type of automobile, legalizing marijuana, and so further.

Complex ill-structured problems require a different educational approach than simple, well-defined ones. To educate people to be able to solve these types of problems we need to choose a whole-task approach, because real-life tasks are not neat segments of some idealized whole, in other words problems designed for the World of Learning. Many researchers (e.g., Hannafin, Land \& Oliver, 1999; Jonassen, 1999; Mayer, 1999; Van Merriënboer, 1997) agree that transfer-oriented learning can best be achieved through the use of realistic learning tasks consisting of a task description, an authentic environment to carry out the task, and cognitive feedback on the quality of the task performance.

This, however, is often easier said than done. Realistic whole tasks are often too difficult for novice learners without some form of simplification. One form of simplification is through segmentation of the whole learning task into smaller task assignments and thereby dividing the problem solving process into phases (Nadolski, Kirschner, Van Merriënboer, \& Hummel, 2001). In other words, dividing whole tasks into non-trivial, authentic part-tasks that often aim at achieving epistemic fluency (Morrison \& Collins, 1996) which is defined as "the ability to identify and use different ways of knowing, to understand their different forms of expression and evaluation, and to take the perspective of others who are operating within a different epistemic framework" (p. 109). Typical epistemic tasks are those which stimulate the learner to describe, explain, predict, argue, critique, explicate, and define (Ohlsson, 1996), since they indicate the discourse-bound activities that learners will have to fulfill during collaborative learning and working. 


\section{Task Control}

Task control is essentially the same as learner control which has had a somewhat fluid and eclectic history. In its broadest sense, learner control is the degree to which a learner can direct his/her own learning experience (Shyu \& Brown, 1992). More specifically, learner control is the degree to which individuals control the path, pace, content and/or contingencies of instruction (Hannafin, 1984). New learning paradigms and new technologies expand this concept of control since they make it possible to provide learners with control over depth of study, range of content, number and type of delivery media, and time spent on learning. With these options, learners can tailor the learning experience to meet their specific needs and interests. For this reason, learner control is not "a unitary construct, but rather a collection of strategies that function in different ways depending upon what is being controlled by whom" (Ross \& Morrison, 1989, p. 29). Indeed, learner control may be a continuum of instructional strategies in which the learner is provided with the option for controlling one or more of the parameters of the learning environment (Parsons, 1991) such as the learning context, the relevant content, the sequencing and pacing of instruction, the availability and type of feedback and reinforcement and possibly even the presentation style. An underlying assumption here is that learners are amply self-sufficient to be given control over their own learning activities and collaboration methods. This point however, is not undisputed (e.g., Clark, 1988).

Finally, task control is increasingly being seen as not being limited to one dimension. There is growing evidence that student-centeredness and teacher-centeredness are two separate dimensions, at least in the perception of students and teachers.

Three Research Projects at the Open University of the Netherlands

What follows are examples of three projects being carried out at the moment of this writing, each of which dealing with one of the three major thrusts of this article, namely: 
- $\quad$ affecting the three defining factors in the educational affording of environments by providing functional roles in collaborating teams,

- designing and implementing social affordances in CSCL environments via the design and implementation of a group awareness widget, and

- applying interaction design in the design of collaborative learning tools in the form of research on the effect of a formalism to support common ground in the solution of complex problems.

\section{Providing Functional Roles}

The first research project discussed here focuses on the effect of functional roles that provide context independent process support - developed for higher education - on group interaction and specifically coordination during project-based learning. CSCL-environments at the Open University of the Netherlands are primarily text-based asynchronous learning systems. Introducing students to the communication and technological tools to support this learning challenges them by figuratively throwing them in the deep end of an unfamiliar realm. An approach to support student groups in such asynchronous communication settings, and the ultimate coordination of their learning, is the use of functional roles in collaborative groups (Brush, 1998). Roles promote group cohesion and responsibility (Mudrack \& Farrell, 1995), thus they can be used to foster positive interdependence and individual accountability contributing in turn to a feeling of (task) ownership.

Since the sense of belonging to a group is essential to team formation (Forsyth, 1999), fucntional roles can provide a social affordance for developing group cohesion and a sense of responsibility, as well as stimulating social interaction between group members. Roles at the same time provide also an educational affordance given the assumption that they decrease coordination communication (i.e., the discussion of who does what) in favor of more taskfocused communication. In addition, the functional roles used are context-independent and 
thus transferable to other content domains in which project-centered work is conducted. The CSCL-environment - the technological affordance offered to the group - is based on only one type of CMC, namely e-mail communication.

\section{Method}

Eighty students enrolled in a course on policy development (49 male and 31 female; Age 23-67 years, Mean $=34.4, \mathrm{SD}=9.03$ ). The design was a quasi-experimental random independent groups design with the manipulation being the introduction of four functional roles in half of the groups (distributed by the members amongst themselves), aimed at promoting the coordination and organization of activities essential for the group project. The other half of the groups was completely self-reliant with respect to organization and coordination of their activities. Each group consisted of four students and throughout the course they communicated electronically by e-mail. Their task was to collaboratively write a policy report containing advice regarding reorganization of local administration, a topical subject in the Netherlands (and a very wicked problem). In terms of the three task constraints that affect group interaction, the task is teacher owned (i.e., set by the teacher), ill-structured (i.e., a complex case study with no single correct answer) and controlled by the students (i.e., although an absolute limit was set by the teacher the students determined their study pace).

To assess the effect of the functional roles on performance, group grades were compared. To assess the effect of the roles on perceived collaboration, each student's selfreport perception of their team development, group process satisfaction, task strategy, level of intra-group conflict, quality of collaboration and usefulness of e-mail were measured. Out of the 80 students enrolled in the course, 43 completed the course successfully (53.8\%), of which 33 students in 10 teams returned the evaluation questionnaire $(76.7 \%)$ : role $(n=5, N=$ 14) and non-role $(\mathrm{n}=5, \mathrm{~N}=19)$. Finally, all e-mail communication of the groups that 
successfully finished the course was analyzed to investigate the actual behavior and the extent to which roles had an effect on coordination and content-focused statements in the messages. Analysis methodology

Multilevel modeling: In research on cooperative learning ANOVA is frequently used to investigate the impact of an instructional strategy using individual level observations (see Slavin, 1995). This type of analysis, however, is not particularly suited to data on student perceptions of group performance since these perceptions depend on the activities of the other group members. Stevens (1996) pointed out that the assumption of independence is violated, which increases as a function of the interdependence in a group, thus yielding a major increase of a Type I error (Snijders \& Bosker, 1999). Multilevel modeling appears better suited to investigate questionnaire data that consists of individual self-report perceptions of group level variables (cf. Bonito, 2002).

Content analysis: The content analysis data consist of the e-mail messages contributed by all group members of those groups that finished the course, regardless whether individual students finished the course or returned the evaluation questionnaire (role and non role; $\mathrm{n}=5$ and $\mathrm{N}=20$ ). All messages were segmented into units of analysis. Strijbos, Martens and Prins (2003) have developed a procedure to segment text-based communication in units defined as a sentence or part of a compound sentence that can be regarded as a meaningful sentence in itself, regardless of coding categories. Punctuation and the word and are used as markers for segmentation, but this is only performed if both parts before and after the marker are a meaningful sentence in itself. Intercoder reliability of two trials was .82 and .89 (proportion agreement), and a cross-validation check on an English language dataset revealed a proportion agreement of .87 (Strijbos, Martens, Jochems, \& Prins, 2003). To analyze the content of these units, a coding scheme was constructed which consists of five main categories: task 
coordination, task content, task social, non task and not codable. Reliability for the coding was acceptable (Cohen's kappa $=.70 ;$ cf. Landis \& Koch, 1977).

For a thorough discussion of the results and methodological considerations (for both the multilevel modeling and content analysis see Strijbos, Martens, Jochems and Broers (in press). For more detail about the content analysis procedure see Strijbos, Martens, Jochems and Prins (2003).

Results

A non-directional Mann-Whitney test revealed no significant differences between conditions with respect to the group grade $(Z=-1.549, d f=4, p>.05)$. Several scales in the self-report questionnaire comprised a single latent variable that was interpreted as perceived group efficiency (PGE).

Multilevel modeling (MLM) was performed on the obtained PGE scores, but the analyses revealed no difference between the 'role' and 'non role' condition regarding PGE using a fixed or random slope model. However, an F-test for homogeneity of variances to investigate the hypothesis of equality of variances in both conditions for the model without random slope $(F=2.86, d f=4, p>.10)$ and the model with random slope $(F=5.86, d f=4$, $.05<p<.10$ ) revealed a tendency with respect to students' awareness of group efficiency. Content analysis corroborates this interpretation.

A non-directional Mann-Whitney test revealed a significant difference with respect to 'task social' statements in the messages $(Z=2.121, d f=4, p<.05)$. The students in the role condition contributed more statements expressing either a positive or negative evaluation or attitude in general, towards the group or towards an individual group member. Furthermore, there were more 'task content' statements in the messages in the role condition $(Z=1.984$, $d f=4, p<.05)$. However, the assumption that this would be due to a decrease in the amount of coordinative statements was not confirmed. In fact, a directional test revealed that the 
amount of coordinative statements in the role groups also increased $(Z=1.776, d f=4$, $p<.05$; one-sided). Apparently, functional roles stimulated coordination and as a result 'task content' statements increased as well $(r=.73, p<.01)$.

The previous reported questionnaire return rates indicate a high dropout rate, but this is not uncommon in distance education (Martens, 1998). A specific comparison of course dropout reveals no differences between conditions. However, a comparison of the total number of students that did not finish the course reveals a significant difference with respect to the distribution $\left(\chi^{2}=6,118, d f=1, \mathrm{p}<.05\right)$. Eighteen students in the 'non role' condition compared to eight students in the 'role' condition - failed to finish the course in time.

\section{Conclusion}

On the one hand, no direct relationship was observed between the instructional intervention and learning outcomes. This is most likely due to a lack of variance, as most grades were between six and eight on a 10-point scale. Moreover, most educators tend not to give unsatisfactory marks to a group, as this would be detrimental to individual group members who invested effort in the group project. On the other hand, content analysis revealed that the assignment of functional roles increased both coordinative and content focused statements, which are important prerequisites for any interaction or collaborative learning to occur. In sum, this study on the function of roles illustrates that sole focus on group performance outcomes in terms of grades (or test results) as indications of successful collaboration is not enough. The study of the environment requires triangulation of research methods and different types of data to construct a representation of the collaborative process.

\section{Designing a Group Awareness Widget}

The aim of the second project is to create sociable environments that meet as much of the social needs of learners through the explicit embedding of social functionality based upon social affordances. Researchers within the area of computer-supported collaborative work 
$(\mathrm{CSCW})$ have already become aware that such sociable environments are needed by virtual groups (Donath, 1997; Feenberg, 1989). Bly, Harrison, and Irwin (1993) argue that the "smooth integration of casual and task-specific interactions, combined with the ability to meet informally as well as formally, is a critical aspect of productive group work" (p. 29). In contrast, they observe that:

\footnotetext{
"Most tools in computer-supported cooperative work (CSCW) are devoted to the computational support of task-specific activities, but support for cooperative work is not complete without considering all aspects of the work group process. When groups are geographically distributed, it is particularly important not to neglect the need for informal interactions, spontaneous conversations, and even general awareness of people and events at other sites" (p. 29).
}

The kind of social affordances we wish to implement focus on stimulation of informal and casual conversations, stimulation of impromptu encounters, and bridging the time gap imposed by asynchronicity. All three aims imply proximity to be an important dimension of social affordances. The first two aims address proximity of place (i.e., spatial proximity) and the latter addresses proximity of time (i.e., temporal proximity) that can be bridged by using traces or footprints which introduce a form of history awareness (Kreijns, Kirschner, \& Jochems, 2003). Up until know this solution of using footprints seems to be appropriate and generally accepted by the community of CSCW and HCI: for example, the concept of social navigation (Munro, Höök, \& Benyon, 1999) is based upon the use of footprints (Wexelblat \& Maes, 1999).

In CSCL environments, social affordance devices may be operationalized by group awareness widgets (GAWs) software tools providing:

1. group awareness for achieving tele-proximity. The group awareness information is presented graphically to the user (i.e., the learner) 
2. history awareness (i.e. the structured collection of all footprints) for achieving an overview of temporal proximities. History awareness information is also presented in a graphical manner to the user.

3. a set of communication media for achieving perception-action coupling.

Based upon the social affordances framework, we implemented a first prototype of a GAW (see Figure 5). As a first step, not all implications of the framework are implemented; the set of communication media contains the traditional communication media (chat and email) and pictures of the participants are used.

\section{****INSERT FIGURE 5 ABOUT HERE****}

The window has a time axis along which strokes are displayed. The stroke length is an indication of the duration of the engagement. Each member is displayed with her or his strokes. Green (dark grey if printed) means on-line, red (also lighter grey if printed) means off-line. Black means that there is no history data available for displaying. As can be seen from Figure 5, history awareness is limited to 11 days; days are separated from each other by small vertical black strokes. Clicking on the portrait of a group member or on a stroke opens a dialog box from which the communication channels are accessible. The dialog box also contains personal and business information about that group member.

We hypothesize that as simple as this single segment of the GAW is, it may already invite the group learner to initiate a communication episode that is not based on the learning tasks to be done. It provides the group member with information that may stimulate social interaction with others in the following ways:

- A group member may perceive that (s)he is not alone in the environment, even in the case that there are no group members currently online; group members may show up at regular times providing opportunities for future contacts in real-time.

- $\quad$ Patterns of busy times become visible. 
- $\quad$ A real-time conversation can be initiated with group members currently online (i.e., a chance encounter) or a message can be sent to a group member who is currently not online.

In addition to the framework of social affordances, the second project also encompasses the concepts of sociability and social presence. The sociability of CSCL environments refers to how they can differ in their ability to facilitate the emergence of a social space; the human network of social relationships between group members which is embedded in group structures of norms and values, rules and roles, beliefs and ideals. Social presence (Short, Williams, \& Christie, 1976) refers to the "degree of salience of the other person in the interaction and the consequent salience of the interpersonal relationships" ( $\mathrm{p}$. 65). It is thus the degree of illusion/perception that the other in the communication appears to be a real physical person. Social presence affects the degree of social interaction taking place in CSCL environments (Gunawardena, 1995; Tammelin, 1998; Tu, 2000, 2002; Tu \& Isaacs, 2002).

To this end, instruments have been developed that measure the degree of sociability, social space, and social presence (Kreijns, Kirschner, Jochems, \& Van Buuren, in press). Testing if and how group awareness affects the degree of sociability, social space, and social presence and eventually leads to better learning in teams is the focus of this research. More precisely, we want to test the following hypotheses:

$\mathrm{H}_{1}$ : Social affordances devices contribute to the degree of perceived sociability of CSCL environments.

$\mathrm{H}_{2}$ : CSCL environments higher in perceived sociability will increase the likelihood of the establishment of a sound social space.

$\mathrm{H}_{3}$ : CSCL environments higher in perceived sociability will increase the degree of perceived social presence. 
$\mathrm{H}_{4}$ : A higher perceived social presence will increase the likelihood of the establishment of a sound social space.

Currently, a series of experiments are being conducted to test the hypotheses. If these hypotheses prove to be true then we may design alternative GAWs that have a complete different look and feeling. We may test the alternatives to examine if they are more powerful in the sense that they are better social affordances devices. Using this strategy may ultimate lead to most satisfying sociable CSCL environments.

\section{Studying a Formalism to Support Common Ground}

When teams have to solve particularly complex, or wicked problems they often face a lack of common ground. The third study discussed here aims at facilitating grounding in such situations (see Beers, Boshuizen, \& Kirschner, 2003 for a more detailed description of this study). The main aim of the research is the interaction design of social/technological affordance devices that invite users to negotiate meaning while collaborating in solving complex problems. This specific project was carried out to determine whether a negotiation widget (i.e., part of a graphical user interface that displays information and invites users to act in a number of ways) would positively affect the process of negotiating common ground.

The process of negotiation starts when a team member makes her/his own as yet unshared knowledge explicit or tangible to others. This can be oral, written, symbolic, et cetera. After one team member has made a contribution, others can try to understand it. In doing this they can consider aspects of the contributor (e.g., educational background, domain of expertise, political views, et cetera) as well as their own beliefs and assumptions. A contribution is thus understood against the presumed perspective of the other, as well as against one's own perspective (Bromme, 2000). According to Clark and Schaefer (1989), the process of grounding continues until "the contributor and the partners mutually believe that the partners have understood what the contributor meant to a criterion sufficient for the 
current purpose" (p. 262). This framework served as the basis for the design of a tool for helping asynchronously collaborating students in teams to achieve common ground.

CSCL environments often make use of external representations formed/restricted by a formalism: a set of objects and rules for making an external representation. In this research a formalism for facilitating negotiation of common ground in problem-solving groups was developed and tested. We expected the formalism to result in more negotiation activities and, ultimately, more common ground. In the research presented we made use of a pen-and-paper approximation of the formalism in an interaction design framework. All six stages of the interaction design model (see Figure 3) were implemented such that - based upon the results of the research reported in this section - the formalism was embedded in a newsgroup environment which is presently being evaluated. The newsgroup was modified to allow the implementation of a widget that defines specific message types (i.e., contribution, clarification, verification, and elaboration) and specific rules about when one was allowed to post messages of certain types.

\section{Method}

We studied students collaborating in a face-to-face setting who were required to make use of a pen-and-paper approximation of the negotiation formalism to solve a complex economics problem derived from a dynamic economics game. First, the participants were allowed to practice with the simulation individually, and to posit a solution to the case individually, so that they were able to fully apply their own perspective to the task. Next, they solved the problem collaboratively, and after that were again asked to formulate an individual solution. All resulting individual problem representations and solutions, as well as the resulting group problem representation and solution, were recorded. The collaboration process was also videotaped for analysis (with Noldus Observer ${ }^{\circledR}$ software). 


\section{Procedure}

Groups using the formalism were compared with groups not using the formalism. In other words groups that worked idiosyncratically. A coding scheme for analysis of negotiation of common ground was developed consisting of the following categories:

- new conversation topics (Contribution),

- $\quad$ verifying one's own understanding of another's utterance (Verification),

- $\quad$ clarifying the intended meaning of a previous utterance as a reaction to a verification (Clarification), and

- $\quad$ continued discussion of a topic, without verifying and clarifying the intended meaning of the utterances (Elaboration).

A high number of clarifications and verifications was seen as indicating explicit negotiation processes. The reliability of the coding and coding procedure was determined by comparing a sample of 25 minutes of video-data ( $9 \%$ of total data) as coded by two coders. This resulted in a substantial (see Landis \& Koch, 1977) inter-rater reliability as determined by a Cohen's kappa of .68 (SE =.066). All further data were coded by one of the coders.

As an indication of common ground, overlap between the individual problem representations of the different participants after problem solving was determined. To do this, discussion topics were identified to characterize the content of individual representations and were subsequently investigated to determine whether they were present in individual representations after collaboration. The extent of overlap between the discussion topics during and after collaboration was used as an indication for common ground.

Results

Results indicated that the formalism-groups spent more time on negotiation than the non-formalism-groups (i.e., groups that used their own idiosyncratic representation method) as reflected by the number of utterances that were representative of negotiation (see Table 1). 
The formalism groups also discussed more different topics than the idiosyncratic groups and more members of the formalism groups participated in discussion (Participants per segment) than in the idiosyncratic groups. These results suggest a more equal representation of the different perspectives in the collaboration process of the formalism groups than in the idiosyncratic groups. We conclude that the formalism affects negotiation processes by making the contributions more explicit.

\section{****INSERT TABLE 1 ABOUT HERE****}

The results on common ground are somewhat less clear (see Table 2). Although the formalism groups discussed more different discussion and their members explicated more different discussion topics in their individual problem representations, the idiosyncratic groups captured more discussion topics in their group external representation than the formalism groups ( $M=13.0$ vs. $M=10.7$, see Table 2$)$. Also, the number of discussion topics was the same for both conditions $(M=2.0$, number of discussion topics in three individual representations), indicating that there was no difference in common ground. A note of caution is needed here. It may have been the case that our choice of describing information content on the contribution level was too crude to see differences in common ground between groups. It remains uncertain whether the formalism influenced the extent to which common ground was negotiated.

\section{****INSERT TABLE 2 ABOUT HERE****}

Based upon these tentative results, both the formalism and the coding scheme have been refined. The formalism was translated into two variations of a negotiation widget for (a)synchronous distributed learning groups. One variant is a non-coercive tool to support users in negotiation. In other words it does not force them to negotiate in a certain way (e.g., every verification must be followed by a clarification or a new concept may not be introduced until the previous one has been fully verified and clarified by all participants). The second 
variant is coercive. Future research will be focused on both the further interaction design of a usable negotiation tool and the effect of coercion on the tools use and value in the negotiation process in solving complex problems.

In sum, these three projects illustrate the importance and impact of affordances technological, educational and social - for designing CSCL environments, as well as the need for interaction design that specifically addresses the issues of user experience which is affected - amongst other critical elements or constraints - by the level of task ownership, task character and task control.

\section{Conclusions}

This article presents a framework for designing and developing electronic collaborative learning environments based upon two separate principles, namely (1) the systemic and emergent properties of educational, social and technological affordances and (2) the implementation of interaction design to assure both usability and utility.

The concept of three types of affordances (i.e., technological, educational, and social) is central to design, specifically in those cases where the learning environment centers on collaboration. Their design and use is an example of studying phenomena in terms of their systemic and emergent properties (in contrast to reductionist thinking which tries to explain system behavior in terms of the behavior of subsystems). In such a way of thinking, CSCL environments are seen as systems that have interacting parts (i.e., artifacts related to technological, educational and social affordances) and emergent properties that exceed the sum of the properties of its parts. With respect to the design of computer-supported learning environments it is not of primary importance what exactly is caused by different elements of the learning environment (learning is no longer causal or deterministic, but has become probabilistic). This has consequences for the approach towards the designing (computersupported) collaborative learning environments. More important is whether the elements of a 
learning environment afford the type of competency development that was targeted. With respect to collaboration, the question is whether the elements of the environment afford the emergence of that type of (social) interaction that is supportive for the acquisition of the targeted competencies.

But these questions cannot be easily answered. We as designers often think that we know what our designs and products will do and how learners will use them. Unfortunately, this is almost never the case. Each of the phases in the design process needs to be studied with respect to the specific choices that can and must be made (see Figure 2). Some research is basic such as studies of interface design or the way information is presented affects cognitive load and learning (e.g., Kester, Kirschner, \& Van Merriënboer, in press). Other studies are more developmental in nature such as research on how group awareness widgets affect the perception of sociability, social space and social presence (Kreijns \& Kirschner, 2002). And still other research is even more applied such as how specific learners or learner groups perceive a specific computer supported learning environment.

Design of CSCL-environments needs to be carried out according to the six stages of the interaction design model presented here (see Figure 3). Though teachers and designers would probably prefer a set of deterministic design rules (i.e., do A, then B to achieve C), a checklist with a limited number of categories is not the answer. We have in this article, however, provided an interaction design model to stimulate educators, educational designers / technologists, and educational researchers to think more deeply about their instructional decisions, and not simply to rely on traditional approaches that "have worked so well". 


\section{References}

Alben, L. (1997). At the heart of interaction design. Design Management Journal, 8(3), 9-26.

Allen, B. S., \& Otto, R. G. (1996). Media as lived environments: The ecological psychology of educational technology. In D. Jonassen (Ed.), Handbook of research for educational communications and technology (pp. 199-226). New York: Simon \& Schuster Macmillan.

Beers, P. J., Boshuizen, H. P. A., \& Kirschner, P. A. (2003, August). Negotiating shared understanding in collaborative problem solving. In S. Järvelä \& F. Fischer (Chairs), Awareness and shared understanding of distributed collaboration: Analysis and facilitation. Paper presented in a symposium conducted at the 10th EARLI biennial meeting, Padova, Italy.

Bly, S., Harrison, S., \& Irwin, S. (1993). Media spaces: Bringing people together in a video, audio, and computing environment. Communications of the ACM, 36(1), 28-47.

Bonito, J. A. (2002). The analysis of participation in small groups: Methodological and conceptual issues related to interdependence. Small Group Research, 33, 412-438.

Bromme, R. (2000). Beyond one's own perspective: The psychology of cognitive interdisciplinarity. In P. Weingart \& N. Stehr (Eds.), Practicing interdisciplinarity (pp. 115-133). Toronto, Canada: University of Toronto Press.

Brush, T. A. (1998). Embedding cooperative learning into the design of integrated learning systems: Rationale and guidelines. Educational Technology, Research \& Development, 46(3), 5-18.

Clark, H. H., \& Schaefer, E. F. (1989). Contributing to discourse. Cognitive Science, 13, 259294.

Clark, R. E. (1983). Reconsidering research on learning from media. Review of Educational Research, 53(4), 445-459. 
Clark, R. E. (1988). When teaching kills learning: Research on mathemathantics. In H. Mandl, E. De Corte, N. Bennett \& H. F. Friedrich (Eds.), Learning and instruction: European research in an international context (Vol. 2.2, pp. 1-22). Oxford, England: Pergamon.

Conklin, E. J., \& Weil, W. (1997) Wicked problems: Naming the pain in organizations. Retrieved January 16, 2003, from http://www.touchstone.com/tr/wp/wicked.html Donath, J. (1997). Inhabiting the virtual city: The design of social environments for electronic communities. Unpublished doctoral dissertation, Massachusetts Institute of Technology, Cambridge, MA.

Feenberg, A. (1989). The written world: On the theory and practice of computer conferencing. In R. Mason \& A. Kaye (Eds.), Mindwave: Communication, computers and distance education (pp. 22-39). Oxford: Pergamon Press.

Forlizzi, J., \& Ford, S. (2000). The building blocks of experience: An early framework for interaction designers. In D. Boyarski \& W. A. Kellogg (Eds.), Conference proceedings on designing interactive systems: Processes, practice, methods, and techniques (pp. 419-423). New York: ACM Press.

Forsyth, D. R. (1999). Group dynamics (3rd ed.). Belmont, CA: Wadsworth.

Gaver, W. W. (1991). Technology affordances. In S. P. Robertson, G. M. Olson \& J. S. Olson (Eds.), Proceedings of the CHI '91 conference on human factors in computing systems: Reaching through technology (pp. 79-84). New Orleans, LA: ACM Press.

Gibson, J. J. (1977). The theory of affordances. In R. Shaw \& J. Bransford (Eds.), Perceiving, acting and knowing (pp. 67-82). Hillsdale, NJ: Erlbaum.

Gunawardena, C. N. (1995). Social presence theory and implications for interaction and collaborative learning in computer conferences. International Journal of Educational Telecommunications, 1(2/3), 147-166. 
Hannafin, M. J. (1984). Guidelines for using locus of instructional control in the design of computer-assisted instruction. Journal of Instructional Development, 7(3), 6-10.

Hannafin, M., Land, S., \& Oliver, K. (1999). Open learning environments: Foundations, methods, and models. In C. M. Reigeluth (Ed.), Instructional-design theories and models: A new paradigm of instructional theory (Vol. 2, pp. 115-140). Mahwah, NJ: Lawrence Erlbaum Associates.

Johnson, D. W. (1981). Student-student interaction: The neglected variable in education. Educational Research, 10, 5-10.

Johnson, D. W., \& Johnson, R. T. (1996). Cooperation and the use of technology. In D. H. Jonassen (Ed.), Handbook of research for educational communications and technology (pp. 1017-1044). New York: Simon \& Schuster Macmillan.

Jonassen, D. H. (1999). Designing constructivist learning environments. In C. M. Reigeluth (Ed.), Instructional design theories and models: A new paradigm of instructional theory (Vol. 2, pp. 371-396). Mahwah, NJ: Lawrence Erlbaum Associates.

Kester, L., Kirschner, P.A., \& Van Merriënboer, J. J. G. (in press). The optimal timing of information presentation during mastering a complex skill in science. International Journal of Science Education.

Kirschner, P. A. (2002). Can we support CSCL? Educational, social and technological affordances for learning. In P. Kirschner (Ed.), Three worlds of CSCL: Can we support CSCL (7-47). Heerlen: Open University of the Netherlands. 
Kirschner, P. A., Martens, R. L., \& Strijbos, J. W. (2004). CSCL in higher education? A framework for designing multiple collaborative environments. In P. Dillenbourg (Series Ed.) \& J. W. Strijbos, P. A. Kirschner \& R. L. Martens (Vol. Eds.), Computersupported collaborative learning: Vol 3. What we know about CSCL ... and implementing it in higher education (pp. 3-30). Boston, MA: Kluwer Academic Publishers.

Kirschner, P. A., Van Merriënboer, J., Carr, C. S., \& Sloep, P. (2002). How expert designers design. Performance Improvement Quarterly, 15(4), 86-104.

Kreijns, K., Kirschner, P. A., Jochems, W., \& Van Buuren, H. (in press). Determining sociability, social space, and social presence in (a)synchronous collaborative groups. Cyberpsychology \& Behavior.

Kreijns, K., Kirschner, P. A., \& Jochems, W. (2003, August). Supporting social interaction for group dynamics through social affordances in CSCL: Group awareness widgets. In P. A. Kirschner (Chair), The social psychological dimension of social interaction and the effects of cultural backgrounds in CSCL. Paper presented in a symposium conducted at the 10th EARLI biennial meeting, Padova, Italy.

Kreijns, K., \& Kirschner, P. A. (2002). Group awareness widgets for enhancing social interaction in computer-supported collaborative learning environments: Design and implementation. In D. Budny \& G. Bjedov (Eds.), Proceedings of the 32nd ASEE/IEEE Frontiers in Education Conference (pp. 436-442). Piscataway, NJ: IEEE.

Kreijns, K., Kirschner, P. A., \& Jochems, W. (2002). The sociability of computer-supported collaborative learning environments. Educational Technology \& Society, 5(1), 8-25.

Krippendorff, K. (1989). On the essential contexts of artifacts or on the proposition that 'design is making sense (of things).' Design Issues, 5(2), 9-39. 
Landis, J., \& Koch, G. (1977). The measurement of observer agreement for categorical data. Biometrics, 33, 159-174.

Löwgren, J. (2002). Just how far beyond HCI is interaction design. Retrieved February 28, 2003, from http://www.boxesandarrows.com/archives/002589.php.

Martens, R. (1998). The use and effects of embedded support devices in independent learning. Utrecht: Lemma.

Mayer, R. E. (1999). Designing instruction for constructivist learning. In C. M. Reigeluth (Ed.), Instructional-design theories and models: A new paradigm of instructional theory (Vol 2., pp. 141-159). Mahwah, NJ: Lawrence Erlbaum Associates.

Merrill, M. D. (2002). First principles of instruction. Educational Technology, Research and Development, 50(3), 43-59.

Mitroff, I. I., Mason, R. O., \& Bonoma, T. V. (1976). Psychological assumptions, experimentation and real world problems. Evaluation Quarterly, 2(4), 639-662.

Morrison, D., \& Collins, A. (1996) Epistemic fluency and constructivist learning environments. In B. Wilson (Ed.), Constructivist learning environments (pp. 107-119). Englewood Cliffs, NJ: Educational Technology Publications.

Mudrack, P. E., \& Farrell, G. M. (1995). An examination of functional role behaviour and its consequences for individuals in group settings. Small Group Research, 26, 542-571.

Munro, A. J., Höök, K., \& Benyon, D. (1999). Social navigation of information space. London: Springer.

Nadolski, R. J., Kirschner, P. A., Van Merriënboer, J. J. G, \& Hummel, H. G. K. (2001). A model for optimizing step size of learning tasks in Competency-based Multimedia Practicals. Educational Technology Research and Development, 49, 87-103.

Nielsen, J. (1993/1994b). Usability engineering. San Fransisco, CA: Morgan Kaufmann Publishers (Original work published 1993, Academic Press). 
Noldus (2003). Noldus Observer ${ }^{\circledR}$ (Version 4) [Computer software]. Wageningen, The Netherlands: Noldus Information Technology bv.

Norman, D. A. (1988). The psychology of everyday things. New York: Basic Books.

Norman, D. A. (1992). Turn signals are the facial expressions of automobiles. Cambridge, MA: Perseus Publishing.

Norman, D. (2002). Emotion \& design: Attractive things work better. Interactions, 9(4), 3642.

Ohlsson, S. (1996). Learning to do and learning to understand. In P. Reimann \& H. Spada (Eds.), Learning in humans and machines (pp. 37-62). Oxford, UK: Elsevier.

Parsons, J. A. (1991). A meta-analysis of learner control in computer-based learning environments. Unpublished doctoral dissertation, Nova University, Fort Lauderdale, Florida, USA.

Preece, J., Rogers, Y., \& Sharp, H. (2002). Interaction design: Beyond human-computer interaction. New York: John Wiley \& Sons.

Preece, J., Rogers, Y., Sharp, H., Benyon, D., Holland, S., \& Carey, T. (1994). Humancomputer interaction. Workingham, UK: Addison-Wesley.

Reeves, T. C. (1993). Pseudoscience in computer-based instruction: The case of learner control research. Journal of Computer-Based Instruction, 20(2), 39-46.

Reigeluth, C.M. (Ed.) (1999). Instructional design theories and models: A new paradigm of instructional theory (Vol. 2). Mahwah, NJ: Lawrence Erlbaum Associates.

Reimann, R. (2001). So you want to be an interaction designer. Newsletter. 2001(6). Retrieved February 28, 2003, from http://www.cooper.com/newsletters/2001_06/2001_06_newsletter.htm. 
Rittel, H. W. J., \& Webber, M. M. (1973/1984). Planning problems are wicked problems. In N. Cross (Ed.), Developments in design methodology (pp. 135-144). Chichester: John Wiley \& Sons. (Originally published as part of Dilemmas in a general theory of planning, Policy Sciences, 4, 1973, 155-169).

Ross, S. M., \& Morrison, G. R. (1989). In search of a happy medium in instructional technology research: Issues concerning external validity, media replications and learner control. Educational Technology, Research and Development, 37(1), 19-33.

Shedroff, N. (2001). Experience design. Indianapolis, IN: New readers.

Short, J., Williams, E., \& Christie, B. (1976). The social psychology of telecommunications. London: John Wiley \& Sons, Ltd.

Shyu, H. Y., \& Brown, S. W. (1992). Learner control versus program control in interactive videodisc instruction: What are the effects in procedural learning? International Journal of Instructional Media, 19(2), 85-95.

Slavin, R. E. (1980). Cooperative learning in teams: State of the art. Educational Psychologist, 15, 93-111.

Slavin, R. E. (1995). Cooperative learning: Theory, research and practice (2nd ed.). Needham Heights: Allyn \& Bacon.

Snijders, T. A. B., \& Bosker, R. J. (1999). Multilevel analysis. Londen: Sage Publications.

Stevens, J. (1996). Applied multivariate statistics for the social sciences (3rd. ed). Mahwah, NJ: Lawrence Erlbaum.

Strijbos, J. W., Martens, R. L., \& Jochems, W. M. G. (in press). Designing for interaction: Six steps to designing computer-supported group-based learning. Computers \& Education. 
Strijbos, J. W., Martens, R. L., Jochems, W. M. G., \& Broers, N. J. (in press). The effect of functional roles on group efficiency: Using multilevel modelling and content analysis to investigate computer-supported collaboration in small groups. Small Group Research.

Strijbos, J. W., Martens, R., \& Prins, F. (2003). Content analysis: What are they talking about?. In B. Wasson, R. Baggetun, U. Hoppe \& S. Ludvigsen (Eds.), CSCL 2003: Community events, communication and interaction (pp. 74-76). Bergen: Intermedia, University of Bergen.

Strijbos, J. W., Martens, R. L., Jochems, W. M. G., \& Prins, F. J. (2003). Content analysis: What are they talking about? Manuscript submitted for publication.

Tammelin, M. (1998). From telepresence to social presence: The role of presence in a network-based learning environment. In S. Tella (Eds.), Aspects of media education: Vol. 8. Strategic imperatives in the information age (pp. 219-231). Helsinki, Finland: Media Education Centre, University of Helsinki, Media Education Publications.

Thackara, J. (2001, June) Why is interaction design so important? In the Bubble. Retrieved February 28, 2003, from http://www.doorsofperception.com/In+the+Bubble/details/17/

Tu, C. H. (2000). On-line learning migration: From social learning theory to social presence theory in a CMC environment. Journal of Network and Computer Application, 23(1), $27-37$.

Tu, C, H. (2002). The impacts of text-based CMC on online social presence. The Journal of Interactive Online Learning, 1(2), 1-24.

Tu, C. H., \& Isaacs, M. (2002). An examination of social presence to increase interaction in online classes. American Journal of Distance Education, 16(3), 131-150. 
Van Merriënboer, J. J. G. (1997). Training complex cognitive skills. Englewood Cliffs, NJ: Educational Technology Publications.

Van Merriënboer, J. J. G., \& Kirschner, P. A. (2001). Three worlds of instructional design: State of the art and future directions. Instructional Science, 29, 429-441.

Wexelblat, A., \& Maes, P. (1999). Footprints: History-rich tools for information foraging. In Proceedings of the SIGCHI conference on Human factors in computing systems: The CHI is the limit (pp. 270-277). New York: ACM Press. 
Table 1.

Differences in use of categories

\begin{tabular}{lcccc}
\hline & \multicolumn{2}{c}{ Mean } & \multicolumn{2}{c}{ Standard deviation } \\
\cline { 2 - 5 } & Formalism & No formalism & Formalism & No formalism \\
\hline Time (s) & 3182 & 2341 & 390.58 & 579.66 \\
Contribution & 25.00 & 19.30 & 4.36 & 4.51 \\
Verification & 38.00 & 19.30 & 5.20 & 8.50 \\
Clarification & 46.00 & 26.70 & 7.21 & 6.66 \\
Elaboration & 118.00 & 102.00 & 34.51 & 17.44 \\
Negotiation ${ }^{\text {a per contribution }}$ & 3.37 & 2.38 & .09 & .58 \\
Participants per segment & 2.67 & 2.47 & .09 & .07 \\
\hline
\end{tabular}

\footnotetext{
${ }^{\mathrm{a}}$ Negotiation $=$ negotiation of meaning $=$ sum of verifications and clarifications.
} 
Table 2.

Common ground

Mean

Standard deviation

\begin{tabular}{llll}
\hline Formalism & No formalism & Formalism & No formalism
\end{tabular}

Total number discussion topics...

25.0

19.3

4.36

4.51

in the group external

$\begin{array}{llll}19.3 & 12.0 & 9.50 & 5.56\end{array}$

representation

$\begin{array}{llll}8.7 & 2.3 & 2.52 & 1.15\end{array}$

in the group solution

6.3

6.3

3.06

2.08

in two individual representations

4.0

2.0

3.00

1.00

in three individual

3.3

2.3

3.08

2.31

representations 
Figure Captions

Figure 1. Two Views on Instructional Design

Figure 2. Usefulness is Determined by Various Types of Affordances

Figure 3. 6-Stage Model of Interaction Design

Figure 4. Three Dimensions of Educational Tasks

Figure 5. The prototype Group Awareness Widget 
Figure 1

Causal design view: World of knowledge

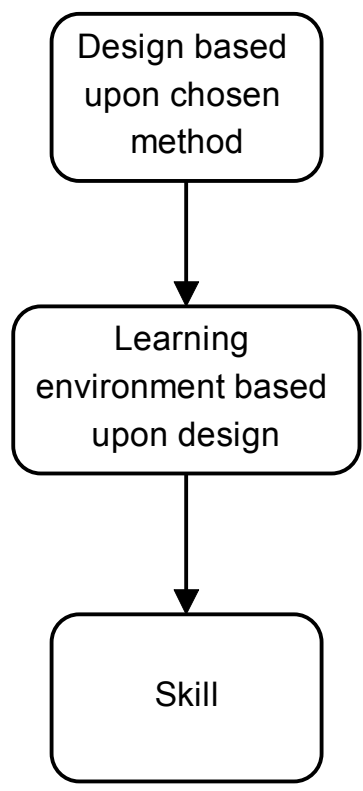

Probabilistic design view:

World of learning

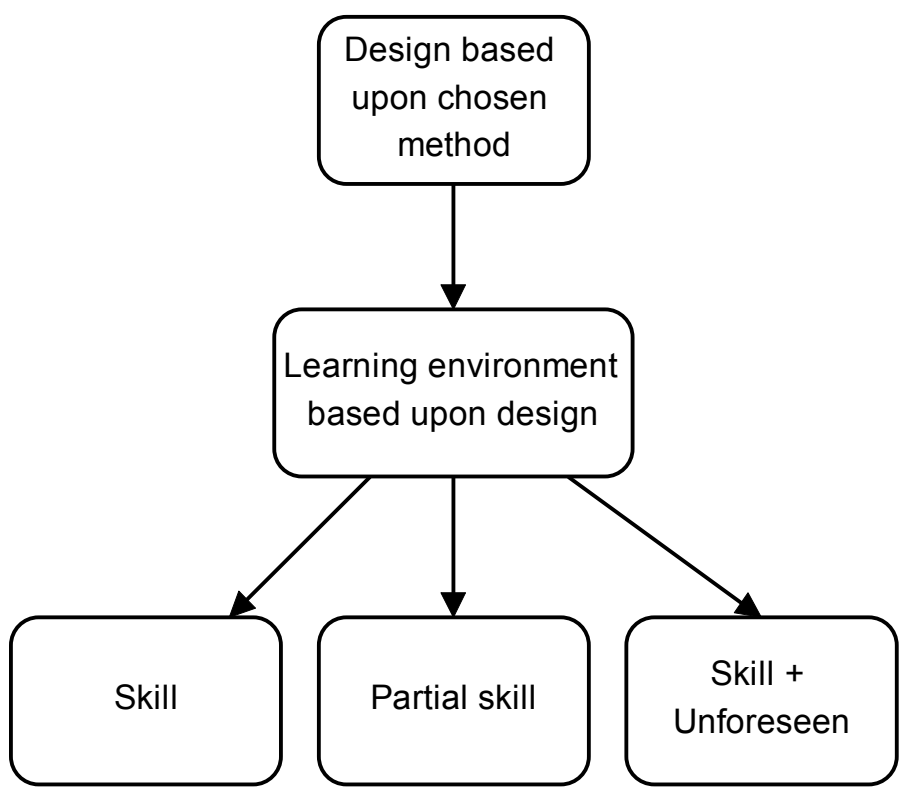


Figure 2

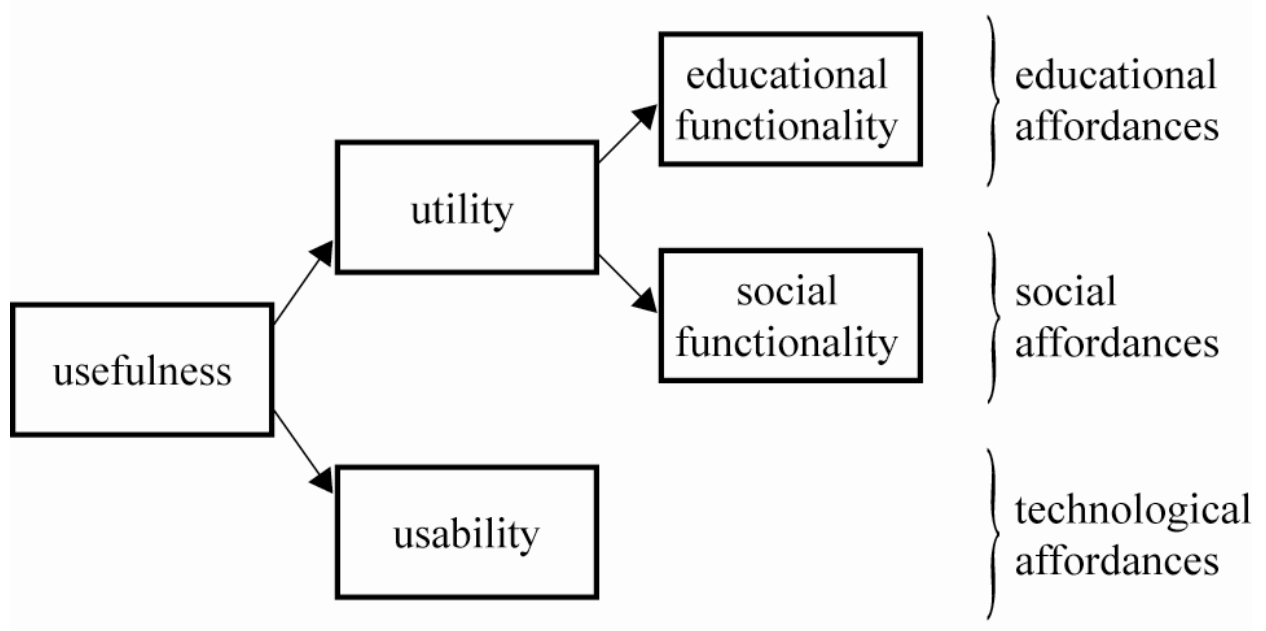


Figure 3

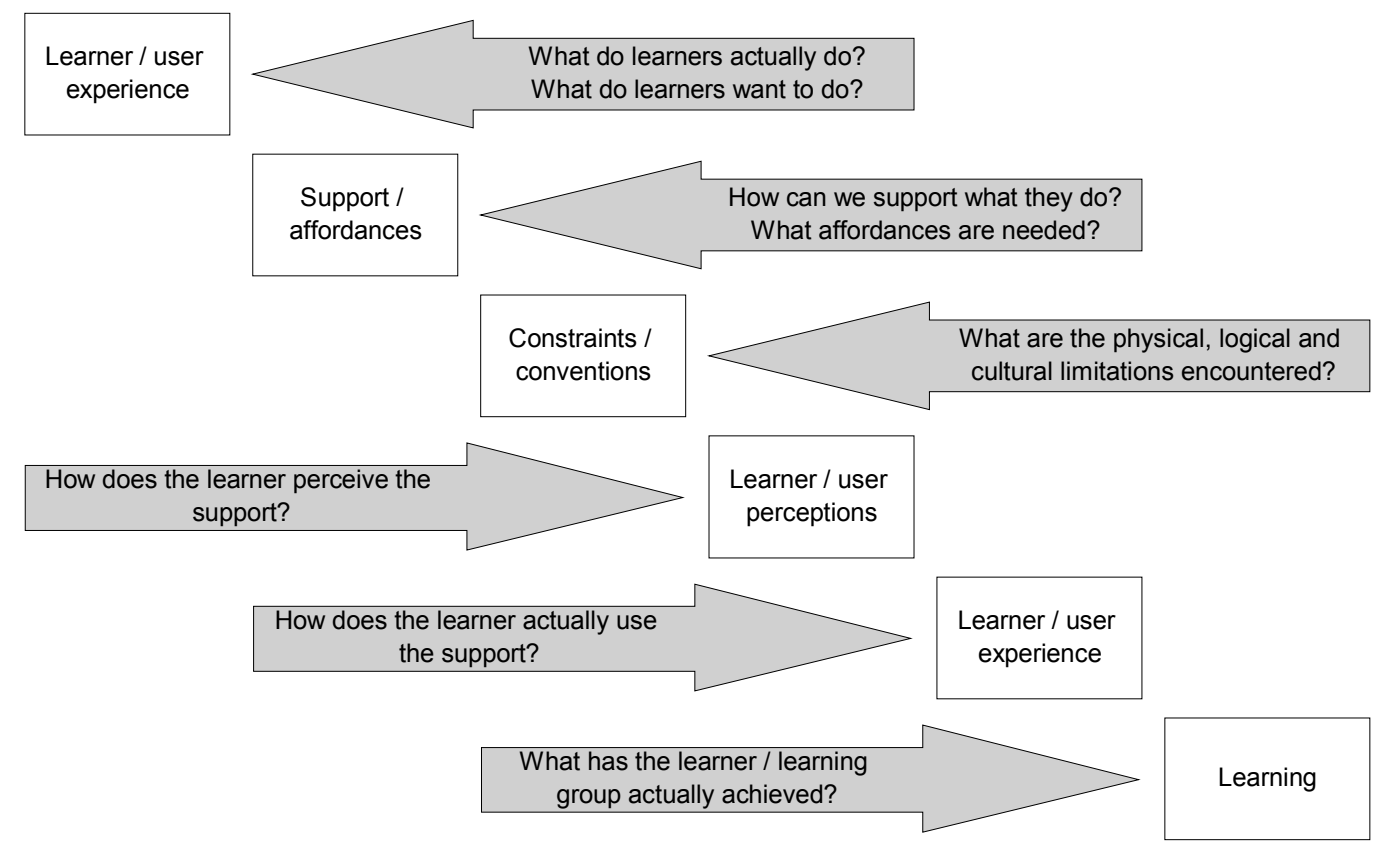


Figure 4

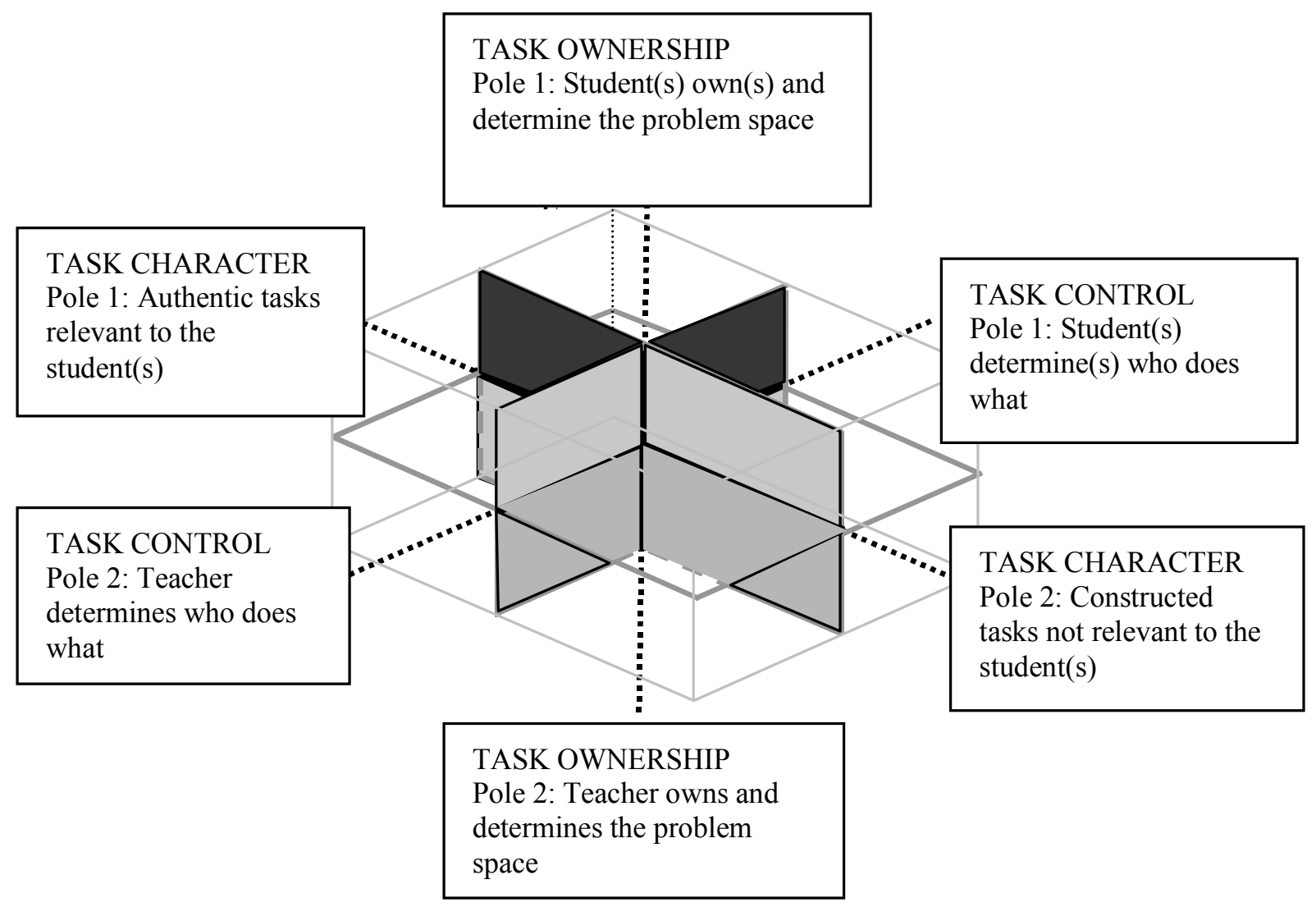


Figure 5

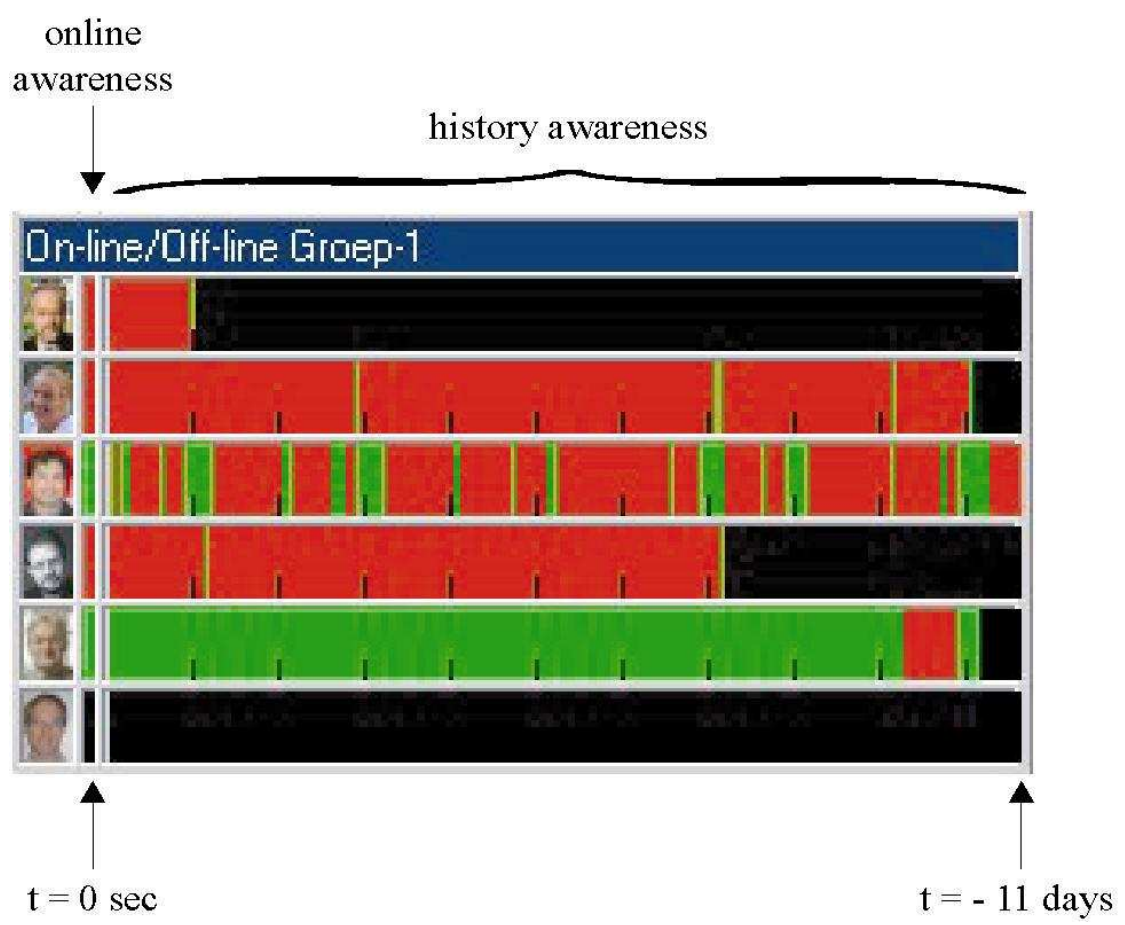

